\title{
Application of Laser-Induced Bone Therapy by Carbon Dioxide Laser Irradiation in Implant Therapy
}

\author{
Takahiro Naka and Satoshi Yokose \\ Division of Operative Dentistry, Department of Conservative Dentistry, Ohu University School of Dentistry, \\ Ohu University School of Dentistry, 31-1 Misumido, Tomita machi, Koriyama, Fukushima 963-8611, Japan \\ Correspondence should be addressed to Satoshi Yokose, s-yokose@den.ohu-u.ac.jp
}

Received 1 September 2011; Accepted 1 November 2011

Academic Editor: Chiaki Kitamura

Copyright ( $\odot 2012$ T. Naka and S. Yokose. This is an open access article distributed under the Creative Commons Attribution License, which permits unrestricted use, distribution, and reproduction in any medium, provided the original work is properly cited.

\begin{abstract}
This study evaluated the application of laser-induced bone therapy (LIBT) to reduce implant healing time in rat tibia. Twenty 10 week-old female Sprague-Dawlay rats were used. The rats received laser irradiation (laser group) or sham operation (control group) on either side of the tibia. Five days after invasion, titanium implants were inserted in proximal tibia. Five, 10, and 20 days after implant placement, tibiae were collected. After taking micro-CT and performing a torque test, the tibiae were decalcified and 8 - $\mu \mathrm{m}$-thick sections were prepared. Specimens were stained with hematoxylin and eosin. Results. Micro-CT images, removal torque values, and histomorphometric analysis data demonstrated a significantly accelerated bone formation in the laser group earlier in the healing process. Conclusion. The use of laser irradiation was effective in promoting bone formation and acquiring osseointegration of titanium implants inserted in rat tibia. LIBT may be suitable for use in implant therapy.
\end{abstract}

\section{Introduction}

Bone formation in peri-implant tissue is a key factor in acquiring osseointegration and maintaining implant stability. However, a longer period for healing and acquiring osseointegration is needed in order to add occlusal load. It has been suggested that a standard healing period of at least 3 months in the mandible and 6 months in the maxilla is needed before implant loading [1-3]. Thus, to speed up the rehabilitation process is still a challenging and important clinical aim.

The skeleton that adapts to mechanical usage and mechanical loading promotes bone formation and remodeling, which is commonly referred to as "Wolff's Law" $[4,5]$ and Frost's theory [6-8]. Mechanical strains such as pulsed electromagnetic fields $[9,10]$ and low-intensity pulsed ultrasound $[11,12]$ are widely accepted. Currently, lasers are commonly used in medical and dental treatment. Clinical applications of lasers are largely divided into low reactive level laser therapy (LLLT) and high reactive level laser therapy (HLLT). LLLT provides photobiological and photochemical effects. LLLT enhanced healing, especially in soft tissues $[13,14]$ such as healing of ulcers [15] and other wounds [16].
Recent research demonstrated that the enhancement of functional attachment of bone-to-titanium implants and promotion of bone mineralization could be achieved by LLLT [17-21]. This would allow the implant to be loaded after a shorter period, reducing the treatment time. A positive effect of LLLT on osseointegration of implants and maturation of peri-implant bone was mainly obtained with Gallium Aluminum Arsenide (GaAlAs) laser [17, 18, 20]. HLLT is useful for cutting biologic materials and producing coagulation necrosis in target tissues with a subsequent reaction in the surrounding tissue. When HLLT is applied to hard tissues such as tooth or bone, carbon dioxide laser $\left(\mathrm{CO}_{2}\right.$ laser $)$ induces extreme cracking and charring of surrounding enamel, dentin, and bone. After HLLT $\mathrm{CO}_{2}$ laser irradiation on rat tibia, disappearance and shrinkage of osteocytes within the lacunae have been observed [22-27]. New bone formation was also observed at the tibial wall adjacent to the marrow cavity under the laser-irradiated cortex [27, 28]. However, HLLT thermal damage results in extensive cell mediated resorption of bone or sequestration of dead bone [29], thus severely limiting the use of HLLT on bone. Currently, $\mathrm{CO}_{2}$ laser is common laser used in dental clinics and it also enables 
rapid and precise tissue destruction, reduces bleeding and postoperative pain, and results in low morbidity, minimal scarring, and wound contracture [30]. However, the application of $\mathrm{CO}_{2}$ laser in dental treatment is restricted to the treatment of soft tissue.

This time, we hypothesized that bone formation occurring within the marrow mediated by HLLT $\mathrm{CO}_{2}$ laser irradiation would accelerate the osseointegration process and reduce healing time. To evaluate our hypothesis, an animal study using functional and morphological analysis was performed.

\section{Material and Methods}

2.1. Experimental Design. The care and use of animals followed "The Guidelines for the Care and Use of Animals" approved by Ohu University in accordance with the principles of the NIH guidelines (approval date: 5/14/2009; Approval number: 2). Twenty 10-week-old female SpragueDawley rats were purchased from Crea Japan (Tokyo, Japan) and used as the experimental model in this study. The right tibia of all rats was treated with laser irradiation, and left tibia was sham operated. Five days after laser irradiation and sham operation, titanium implants were placed. Briefly, under general anesthesia, the surface of the proximal metaphases of the tibiae was exposed by an incision approximately $10 \mathrm{~mm}$ in length. Under constant saline irrigation, a bicortical implant bed was drilled with a dental bur at a rotary speed not exceeding $1500 \mathrm{rpm}$, and the implant was placed until the screw thread completely penetrated the bone cortex. After installation, the soft tissue was replaced and sutured. After these procedures, the animals were housed with free access to water and provided a diet. Care was taken to avoid unnecessary stress and discomfort to the animal throughout the experimental period. Five animals were sacrificed 5, 10, or 20 days after implantation, and tibiae containing implants were collected (Figure 1).

2.2. $\mathrm{CO}_{2}$ Laser. In this experiment, $\mathrm{CO}_{2}$ laser (NANOLASER GL-III, GC Co., Tokyo, Japan, and OPELASER Lite, Yoshida Co., Tokyo, Japan) was used at a wavelength of $10.6 \mu \mathrm{m}$, a diameter of $1.70 \mathrm{~mm}$, output of $1.0 \mathrm{~W}$, and a continuous wave form. The laser beam was focused by maintaining $10 \mathrm{~mm}$ delivery tip-to-target surface distance. Total irradiated energy was $220.4 \mathrm{~J} / \mathrm{cm}^{2}$.

2.3. Titanium Implant. Screw-shaped implants made from commercially pure titanium were used in this study (Nishimura Co., Ltd., Fukui, Japan). The total length of each implant was $2 \mathrm{~mm}$, thread diameter $1.4 \mathrm{~mm}$, and pitch $0.6 \mathrm{~mm}$. Implants were cleaned in absolute ethanol in an ultrasonic bath and sterilized by autoclaving.

2.4. Microtomographic Histomorphometry (Micro-CT). After sacrificing the rats, tibiae with titanium implants were collected, and microtomographic histomorphometry was performed with a high-resolution micro-CT system (TOSCANER-30000, Toshiba IT and Control Systems Co., Tokyo,



FIGURE 1: Experimental protocol. Time schedule of bur/laser injury, implant placement, and subsequent healing periods.

Japan). The Computed tomography parameters were as follows: (1) the image pixel size was set to $1024 \times 1024$; (2) the slice thickness was set to $0.05 \mathrm{~mm}$; (3) the image magnification was set to $10 \mathrm{x}$; (4) the X-ray tube voltage was set to $100 \mathrm{kV}$; (5) the anode electrical current was set to $80 \mu \mathrm{A}$. Three dimensional images were reconstructed using the microreconstruct software (Simplant Pro, Materialise Dental Japan Inc., Tokyo, Japan.).

2.5. Torque Test. After stabilization of the implanted tibia, the force needed to unscrew the implants was measured using a Tohnichi Torque driver FTD2-S (Tohnichi Mfg. Co., Ltd., Tokyo, Japan). It has a round dial gauge with a pointer to read the peak value. Peak value when the rupture occurred between implant and bone was recorded, and the mean torque measurements were calculated for each implant inserted into the tibia specimen.

2.6. Histomorphometric Procedure. After removing the titanium implants, collected tibiae were fixed in $10 \%$ phosphatebuffered neutral formalin ( $\mathrm{pH}$ 7.4) (Wako Pure Chemical Industries, Ltd., Osaka, Japan), decalcified in $0.5 \mathrm{~mol} / \mathrm{L}$ EDTA ( $\mathrm{pH}$ 7.5) (Wako Pure Chemical Industries) for 2 weeks at $4^{\circ} \mathrm{C}$, dehydrated in an ethanol (Wako Pure Chemical Industries) series, washed in xylene (Wako Pure Chemical Industries), and then embedded in paraffin. Decalcified $8-\mu \mathrm{m}$ thick sections were made and stained with hematoxylin and eosin (H\&E) for general morphological analysis.

2.7. Statistical Analysis. For biomechanical testing analysis, a two-way analysis of variance was used to examine the influence on osseointegration of (1) laser or sham operated and (2) the length of the healing period. Differences with a $P$ value less than 0.05 were considered significant.

\section{Results}

3.1. Osteoid Formation (Figure 2). To examine the correlation between total irradiated energy and osteoid formation capacity, we evaluated four kinds of energy densities, 88.2, $220.4,441.0$, and $661.5 \mathrm{~J} / \mathrm{cm}^{2}$. Five days after laser irradiation, a char layer, empty osteocytic lacunas were observed. The osteocytic lacunae in most of the cortical bone appeared to be devoid of osteocytes because the typical blue-purple staining of osteocytic nuclei was absent on H\&E staining. 


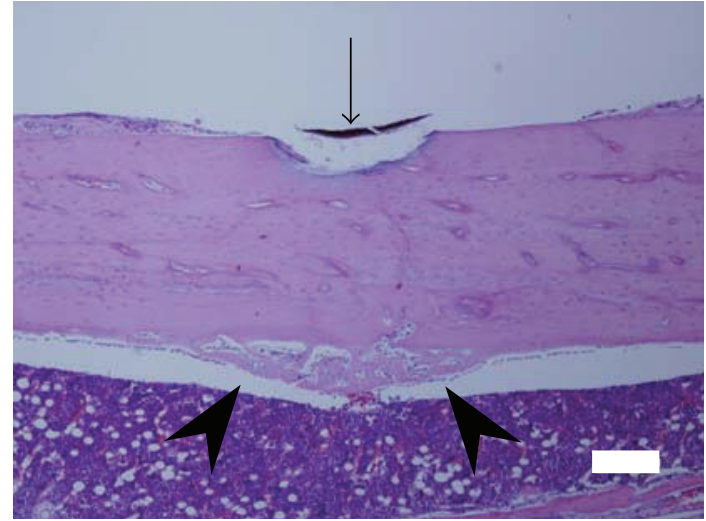

(a)

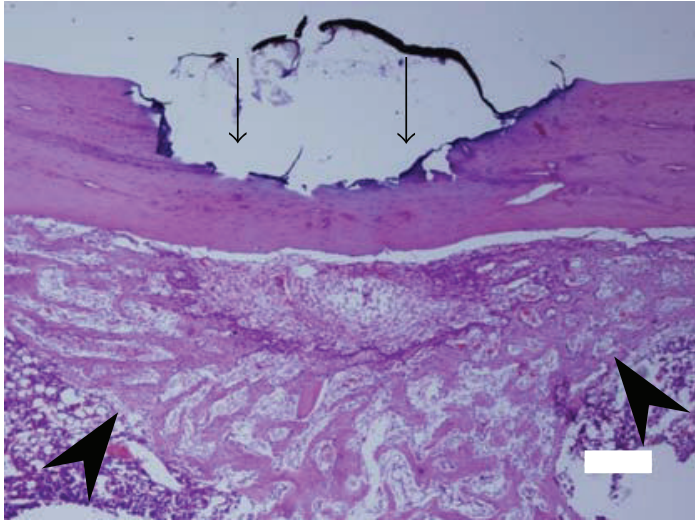

(c)

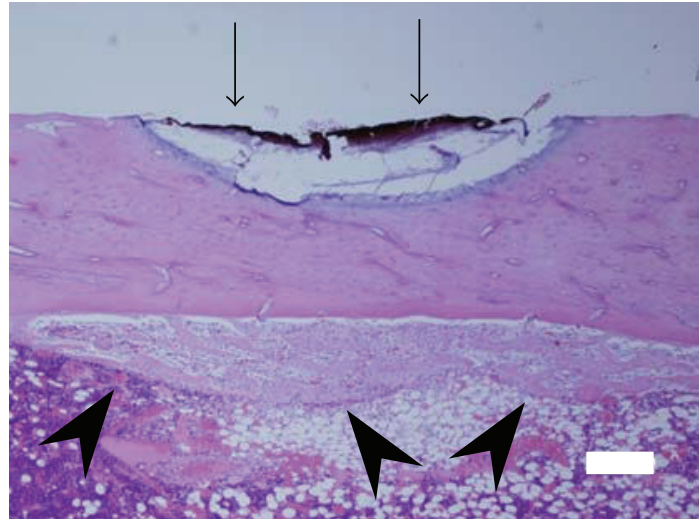

(b)

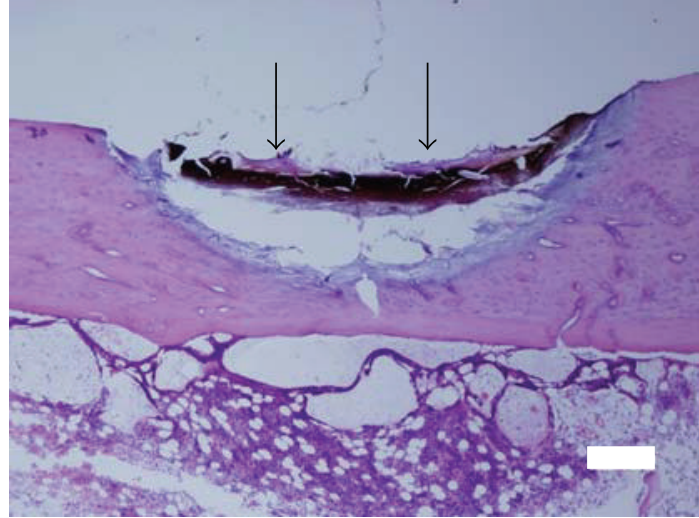

(d)

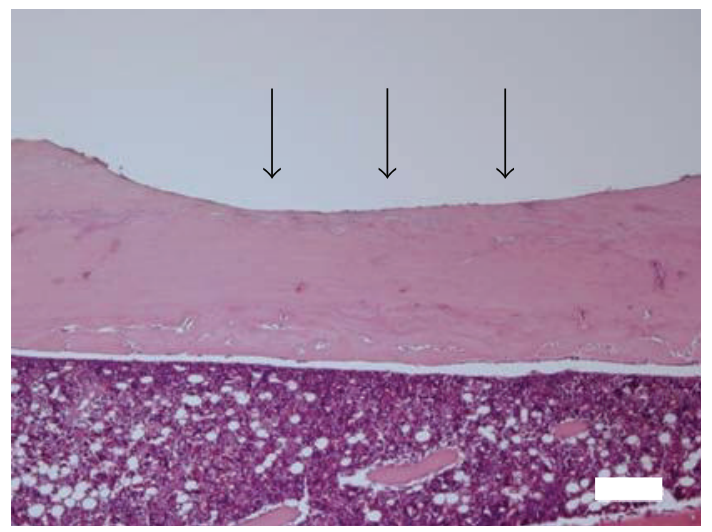

(e)

Figure 2: Comparison of osteoid formation in the bone marrow space in the laser-irradiated group and bur-injured group 5 days after treatment. (a) laser-irradiated tibia. Energy density $=88.2 \mathrm{~J} / \mathrm{cm}^{2}$, (output: $1.0 \mathrm{~W}$, irradiation time: $2 \mathrm{sec}$ ). (b) laser-irradiated tibia. Energy densities $=220.5 \mathrm{~J} / \mathrm{cm}^{2}$, (output: $1.0 \mathrm{~W}$, irradiation time: $5 \mathrm{sec}$ ). (c) laser-irradiated tibia. Energy densities $=441.0 \mathrm{~J} / \mathrm{cm}^{2},($ output: $1.0 \mathrm{~W}$, irradiation time: $10 \mathrm{sec}$ ). (d) laser-irradiated tibia. Energy densities $=661.5 \mathrm{~J} / \mathrm{cm}^{2}$, (output: $1.0 \mathrm{~W}$, irradiation time: $15 \mathrm{sec}$ ). (e) bur-injured tibia. (a-d) laser-irradiated tibia showed an ablation defect, carbon deposits, and numerous empty osteocytic lacunae. Moreover, newly formed trabecular bone was observed on the marrow side of the laser-treated site $(\mathrm{a}-\mathrm{c})$. (e) bur-injured tibia showed a slight amount of reactive bone formation on the endosteal surface. H\&E stain with 40x magnification. Bar $=200 \mu \mathrm{m}$. Arrow indicates laser-irradiated or bur-injured site. Arrow heads indicate osteoid formation site.

Moreover, as energy densities increased, the depth of ablation and width of surface damage increased (Figures 2(a)-2(d)). Osteoid formation just under the irradiated cortical bone was observed in the $88.2,220.5$, and $441.0 \mathrm{~J} / \mathrm{cm}^{2}$ groups tibia (Figures 2(a)-2(c)). In the $441.0 \mathrm{~J} / \mathrm{cm}^{2}$ group tibia, no osteoid formation was observed (Figure 2(d)). In the bur injured tibia, a cortical bone defect and a small amount of reactive bone formation in the bone marrow space were observed (Figure 2(e)). From this observation, we used $220.5 \mathrm{~J} / \mathrm{cm}^{2}$ to this experiment. 


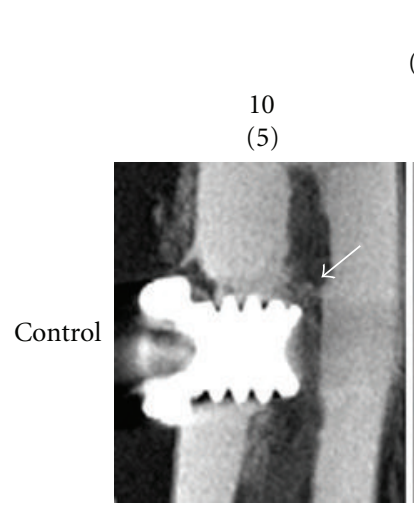

(a)

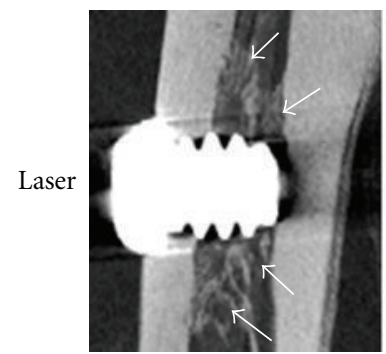

(d)

\begin{abstract}
Days after injury (Days after implantation)
\end{abstract}

15

(10)

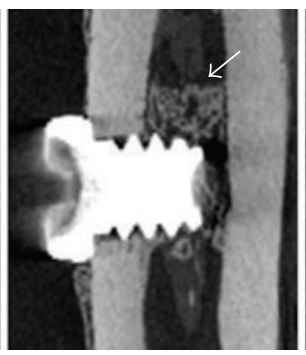

(b)

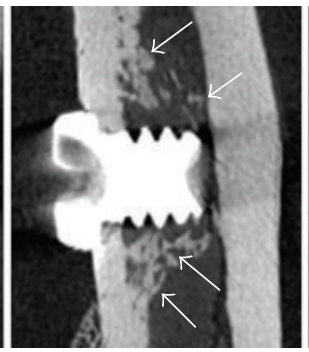

(e)
25

(20)

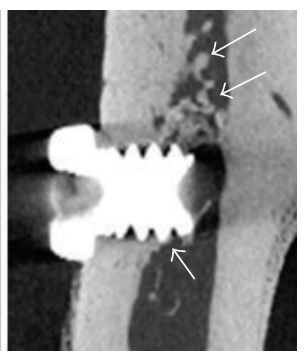

(c)



(f)

Figure 3: Micro-CT images. (a, d): 5 days after implantation (10 days after sham operation or laser irradiation). (b, e): 10 days after implantation (15 days after sham operation or laser irradiation). (c, f): 20 days after implantation (25 days after sham operation or laser irradiation). (a-c): control group tibia. $(\mathrm{d}-\mathrm{f})$ : laser group tibia. Arrow indicates newly formed bone.

3.2. Micro-CT Observation of Tibia (Figure 3). Ten days after injury (5 days after implantation), little radiopacity was observed around the implant body in the bur-implant group tibia. In the laser group tibia, evident radiopacity was observed around the titanium implant.

Fifteen days after injury (10 days after implantation), beginning of evident radiopacity was observed around titanium implant body in the control group. In the laser group tibia, increased radiopacity was observed around the titanium implant.

Twenty-five days after injury (20 days after implantation), obvious radiopacity, though thinner than that in the laser group, was observed around the implant body. In the laser group tibia, thick radiopacity was observed around the implant body.

3.3. Removal Torque Test (Figure 4). Functional attachment of the integration between implants and bone was evaluated using a torque test with torque drivers.

Ten days after injury ( 5 days after implant placement), the average removal torque was $0.63 \pm 0.18 \mathrm{~N} \mathrm{~cm}$ for the control group and $1.36 \pm 0.15 \mathrm{~N} \mathrm{~cm}$ for the laser group. There was a significant difference between the laser and control groups.

Fifteen days after injury (10 days after implant placement), the average removal torque was $0.68 \pm 0.15 \mathrm{~N} \mathrm{~cm}$ for the control group and $1.65 \pm 0.21 \mathrm{~N} \mathrm{~cm}$ for the laser group. There was a statistically significant difference between the laser and control groups.
Twenty-five days after injury (20 days after implant placement), the average removal torque was $0.89 \pm 0.16 \mathrm{~N} \mathrm{~cm}$ for the control group and $1.87 \pm 0.28 \mathrm{~N} \mathrm{~cm}$ for the laser group. There was a significant difference between the laser and control groups. Moreover, there were significant differences between 25-day value of control group and 10- or 15-day value of laser group.

\subsection{Histological Findings (Figure 5)}

3.4.1. Day 10 (Figures 5(a) and 5(d)). Ten days after injury (5 days after titanium implant insertion), hematoma, soft tissue, and little bone fragment formation were observed around the inserted titanium implant in the control group tibia (Figure 5(a)). In the laser group tibia, a large amount of bone matrix had formed along the bone-implant interface (Figure 5(d)).

3.4.2. Day 15 (Figures 5(b) and 5(e)). Fifteen days after injury (10 days after titanium implant insertion), formation of woven bone was observed around the inserted titanium implant in the control group tibia (Figure 5(b)). In the laser group, most of the implant surface was in direct contact with the new woven bone (Figure 5(e)).

3.4.3. Day 25 (Figures 5(c) and 5(f)). Twenty-five days after injury (20 days after titanium implant insertion), the implant surface was also covered with newly formed bone in the control group tibia. But the trabecular bone was thinner than 


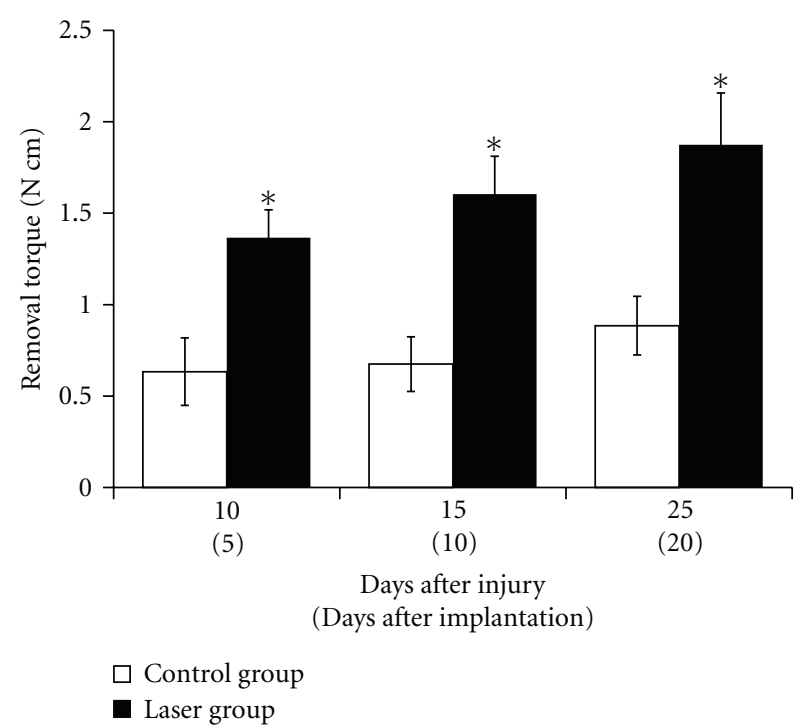

Figure 4: Removal torque examination of titanium implant. Removal torque values were measured at different time points. Mean \pm $\mathrm{SE}(\mathrm{N} \mathrm{cm})$ of torque forces in laser group and control group. Five days after implantation, significant difference was observed between the control and laser groups. Until twenty days after implantation, there was still a significant difference between the two groups. ${ }^{*} P<$ 0.05 .

that in the laser group (Figure 5(c)). In the laser group, most of the implant surface was covered with thick newly formed bone lamella, which was connected with preexisting bone by newly formed trabeculae. Moreover, osteocytes were apparent in the newly formed bone matrix surrounding the implant (Figure 5(f)).

\section{Discussion}

$\mathrm{CO}_{2}$ laser emits a beam of energy that lases tissues in a noncontact mode. HLLT $\mathrm{CO}_{2}$ laser irradiation is known to produce a photobiodestructive reaction inducing cellular vaporization, whereas LLLT $\mathrm{CO}_{2}$ laser therapy generates a photobioactive reaction (PAR) stimulating cellular proliferation and differentiation [31]. $\mathrm{CO}_{2}$ laser has a wavelength of $10.6 \mu \mathrm{m}$, which falls within the specific absorption spectrum for calcium hydroxyapatite, 9.0 to $11.0 \mu \mathrm{m}$ [32]. Moreover, previous report indicated that when laser irradiation was performed on the cortical bone, only $\mathrm{CO}_{2}$ laser could induce newly bone formation in the marrow cavity [26]. Based on this observation, the mineral components of bone are expected to exhibit maximal absorption of the laser energy. It seems reasonable to assume that $\mathrm{CO}_{2}$ laser irradiation of the bone tissue would be suitable for bone regeneration therapy. However, it is commonly accepted that $\mathrm{CO}_{2}$ laser is unable to use hard tissue treatment.

The bone tissue that received laser irradiation demonstrated acceleration of bone formation. Bone formation induced by $\mathrm{CO}_{2}$ laser has also been reported previously [24$26,33,34]$. As cellular mechanisms of this reactive bone formation have been obscure, we speculated that osteocytes have been capable of playing a part. In fact, Tasumi et al. reported that bone formation in tibiae of transgenic mouse model in which specific ablation of osteocytes have been accelerated drastically [35]. They pointed out that mature osteocytes express Sclerostin, the negative regulator of osteoblastic bone formation by antagonizing BMP and Wnt signal. Moreover, the expression of Sclerostin was decreased followed by osteocytes ablation in the transgenic mouse model, which may cause stimulation of bone formation. In this present study, judging from osteocytic appearances with pyknotic, shrunken, and displaced cells within their lacunae, laser irradiation locally damaged osteocytes. Damaged osteocytes mediated by laser irradiation also decreased sclerostin expression; the bone formation could be stimulated. However, it is necessary to analyze what is the negative and/or positive regulator of osteocyte-derived factors induced by laser irradiation. Further investigation will be required to clarify this point.

However, laser irradiation also induced not only damage of cortex but also induced the inflammatory reaction and degeneration of bone marrow. In this study, we inserted titanium implant to the damaged cortex and bone marrow. To achieve the early healing and lording, osseointegration of screw neck to cortical bone is important. Additional studies are needed to clarify the effective irradiation energy to minimize the heat damaged cortical bone and bone marrow inflammatory reaction in order to apply this method to dental implant therapy.

To confirm whether laser-induced bone therapy (LIBT) was effective in implant therapy, we inserted a titanium implant into woven bone and evaluated the bone formation. Although an implant has the ability to induce bone formation around itself, we hypothesized that bone formation occurring within the marrow prior to implant insertion would accelerate the osseointegration process and reduce healing time. To evaluate our hypothesis, we used histomorphological and clinical parameters to evaluate the degree of bone formation and osseointegration. Micro-CT image analysis [36], removal torque measurements [37-43], and histomorphometric evaluation [21,43-47] are currently considered standard analyses in implant research. In the early healing stage, advancement of histomorphological changes and significantly increased functional analysis data were observed in the laser-implant group. These results may be attributed to the laser-mediated bone formation in the marrow area. These results suggest that preoperative HLLT treatment may promote formation of bone tissue with a tighter mesh of trabeculae, which promotes early osseointegration.

Many signaling molecules, such as growth factors and hormones, are involved in bone metabolism [48, 49], especially around the titanium implant [50]. Further investigations are needed to focus on the underlying biological mechanisms, which induce osseointegration in implant therapy when using LIBT.

In this experimental model, the application of LIBT before implant insertion may promote bone formation and facilitate osseointegration of titanium implants (Figure 6). The introduction of LIBT in implant treatment seems 


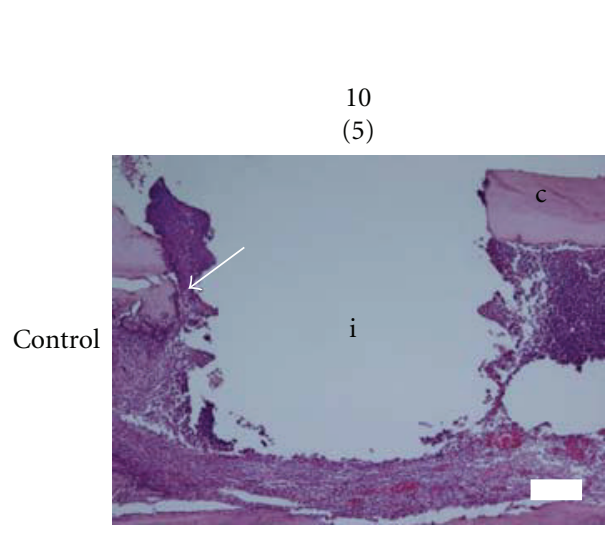

(a)

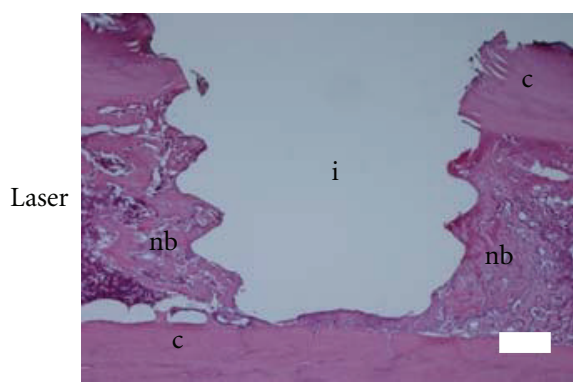

(d)
Days after injury

(Days after implantation)

15

(10)

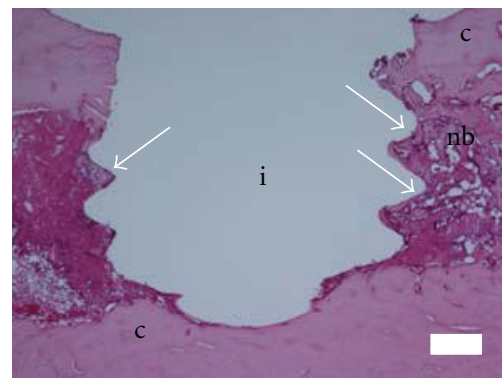

(b)

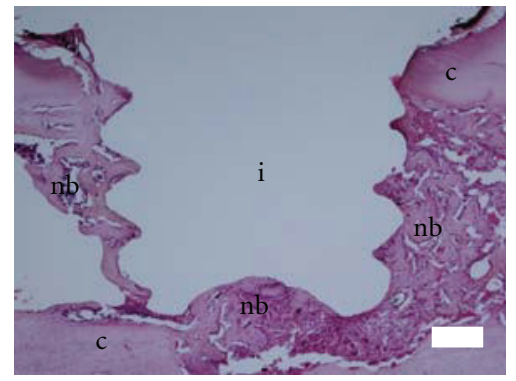

(e)
(20)

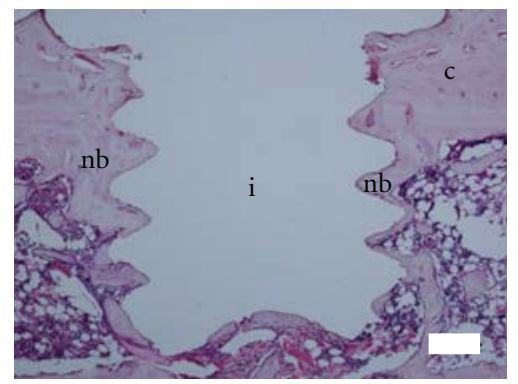

(c)

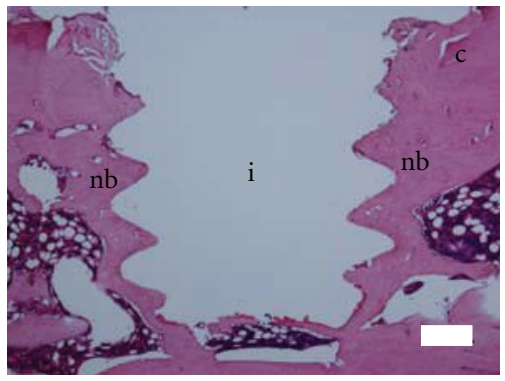

(f)

FIgURE 5: H\&E staining observation. (a, d): 5 days after implantation (10 days after sham operation or laser irradiation). (b, e): 10 days after implantation (15 days after sham operation or laser irradiation). (c, f): 20 days after implantation (25 days after sham operation or laser irradiation). (a-c): control group tibia. (d-f): laser group tibia. In the early healing period (10 days after injury), in the control group, there was limited bone formation around the implant body, while in the laser group, there was obvious bone formation along the inserted implant. Fifteen days after injury, in the control group, tibia showed little osteoid formation around the implant body. In the laser group, thick and abundant bone formation was evident along the inserted implant body. Twenty-five days after injury, in the control group, tibia showed newly formed cortical bone, but the trabecular bone was thinner than that in the laser group tibia. In the laser group, thick cortical bone was connected to the previously existing cortex. H\&E stain with 40x magnification. c: cortical bone, i: implant cavity, nb: newly formed bone, bar $=200 \mu \mathrm{m}$.

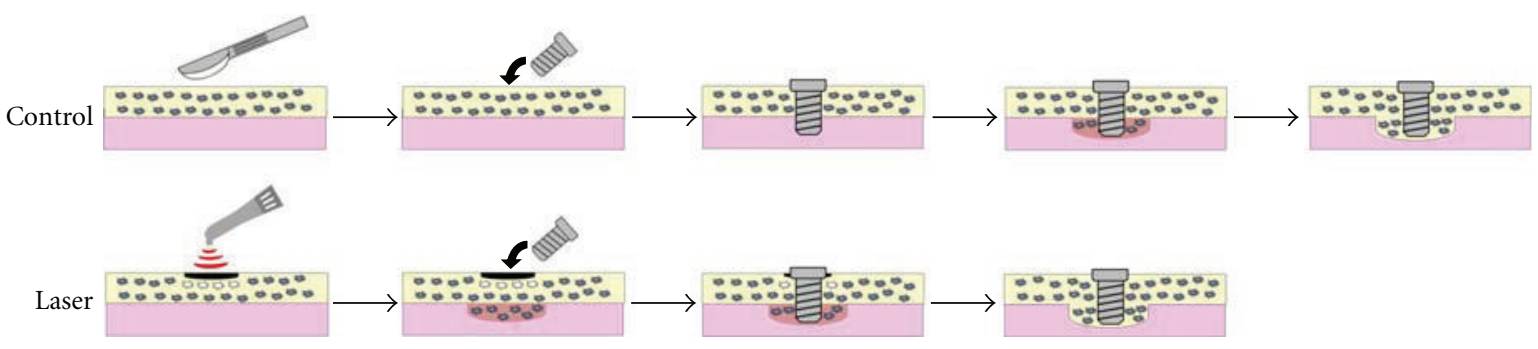

FIGURE 6: Summary of the healing processes in the control group and laser group. Laser irradiation-induced bone formation in the bone marrow and laser group showed earlier osseointegration. The control group also acquired osseointegration, but the healing period was longer than that of the laser group.

feasible and may be of therapeutic benefit in accelerating healing.

\section{Acknowledgment}

This study was partially supported by a Grant-in-Aid for Scientific Research from the Ministry of Education, Science, Sports, and Culture, Japan (22791843).

\section{References}

[1] P. I. Brånemark, G. A. Zarb, and T. Albrektsson, Tissue Integrated Protheses: Osseointegration in Clinical Dentistry, Quintessence, Chicago, Ill, USA, 1985.

[2] R. Adell, U. Lekholm, B. Rockler, and P. I. Branemark, "A 15year study of osseointegrated implants in the treatment of the edentulous jaw," International Journal of Oral Surgery, vol. 10, no. 6, pp. 387-416, 1981. 
[3] T. Albrektsson, G. Zarb, P. Worthington, and A. R. Eriksson, "The long-term efficacy of currently used dental implants: a review and proposed criteria of success," The International Journal of Oral \& Maxillofacial Implants, vol. 1, no. 1, pp. 1125, 1986.

[4] J. Wolff, Das Gesetz der Transformation der Knochen, Springer, Berlin, Germany, 1892, Translated as The Law of Bone Remodeling.

[5] H. M. Frost, "Wolff's Law and bone's structural adaptations to mechanical usage: an overview for clinicians," Angle Orthodontist, vol. 64, no. 3, pp. 175-188, 1994.

[6] H. M. Frost, "Bone "mass" and the "mechanostat": a proposal," Anatomical Record, vol. 219, no. 1, pp. 1-9, 1987.

[7] H. M. Frost, "Perspectives: a proposed general model of the "Mechanostat" (suggestions from a new skeletal-biologic paradigm)," Anatomical Record, vol. 244, no. 2, pp. 139-147, 1996.

[8] J. M. Hughes and M. A. Petit, "Biological underpinnings of frost's mechanostat thresholds: the important role of osteocytes," Journal of Musculoskeletal Neuronal Interactions, vol. 10, no. 2, pp. 128-135, 2010.

[9] R. A. Luben, C. D. Cain, and M. C. Y. Chen, "Effects of electromagnetic stimuli on bone and bone cells in vitro: inhibition of responses to parathyroid hormone by low-energy lowfrequency fields," Proceedings of the National Academy of Sciences of the United States of America, vol. 79, no. 13, pp. 4180 4184, 1982.

[10] R. J. Fitzsimmons and D. J. Baylink, "Growth factors and electromagnetic fields in bone," Clinics in Plastic Surgery, vol. 21, no. 3, pp. 401-406, 1994.

[11] J. A. Spadaro and S. A. Albanese, "Application of low-intensity ultrasound to growing bone in rats," Ultrasound in Medicine and Biology, vol. 24, no. 4, pp. 567-573, 1998.

[12] S. J. Warden, K. L. Bennell, M. R. Forwood, J. M. McMeeken, and J. D. Wark, "Skeletal effects of low-intensity pulsed ultrasound on the ovariectomized rodent," Ultrasound in Medicine and Biology, vol. 27, no. 7, pp. 989-998, 2001.

[13] E. Mester, T. Spiry, B. Szende, and J. G. Tota, "Effect of laser rays on wound healing," The American Journal of Surgery, vol. 122, no. 4, pp. 532-535, 1971.

[14] S. Rochkind, V. Drory, M. Alon, M. Nissan, and G. E. Ouaknine, "Laser phototherapy $(780 \mathrm{~nm})$, a new modality in treatment of long-term incomplete peripheral nerve injury: a randomized double-blind placebo-controlled study," Photomedicine and Laser Surgery, vol. 25, no. 5, pp. 436-442, 2007.

[15] E. Mester, A. F. Mester, and A. Mester, "The biomedical effects of laser application," Lasers in Surgery and Medicine, vol. 5, no. 1, pp. 31-39, 1985.

[16] B. Braverman, R. J. McCarthy, A. D. Ivankovich, D. E. Forde, M. Overfield, and M. S. Bapna, "Effect of helium-neon and infrared laser irradiation on wound healing in rabbits," Lasers in Surgery and Medicine, vol. 9, no. 1, pp. 50-58, 1989.

[17] G. A. Guzzardella, P. Torricelli, N. Nicoli-Aldini, and R. Giardino, "Osseointegration of endosseous ceramic implants after postoperative low-power laser stimulation: an in vivo comparative study," Clinical Oral Implants Research, vol. 14, no. 2, pp. 226-232, 2003.

[18] M. Khadra, N. Kasem, S. P. Lyngstadaas, H. R. Haanaes, and K. Mustafa, "Laser therapy accelerates initial attachment and subsequent behavior of human oral fibroblasts cultured on titanium implant material. A scanning electron microscope and histomorphometric analysis," Clinical Oral Implants Research, vol. 16, no. 2, pp. 168-175, 2005.

[19] C. B. Lopes, A. L. B. Pinheiro, S. Sathaiah, J. Duarte, and M. C. Martins, "Infrared laser light reduces loading time of dental implants: a raman spectroscopic study," Photomedicine and Laser Surgery, vol. 23, no. 1, pp. 27-31, 2005.

[20] Y. D. Kim, S. S. Kim, D. S. Hwang et al., "Effect of low-level laser treatment after installation of dental titanium implantimmunohistochemical study of RANKL, RANK, OPG: an experimental study in rats," Lasers in Surgery and Medicine, vol. 39, no. 5, pp. 441-450, 2007.

[21] C. L. Pereira, E. A. Sallum, F. H. Nociti, and R. W. F. Moreira, "The Effect of low-intensity laser therapy on bone healing around titanium implants: a histometric study in rabbits," International Journal of Oral and Maxillofacial Implants, vol. 24, no. 1, pp. 47-51, 2009.

[22] G. M. Rayan, J. V. Pitha, J. S. Edwards, and R. B. Everett, "Effects of $\mathrm{CO}_{2}$ laser beam on cortical bone," Lasers in Surgery and Medicine, vol. 11, no. 1, pp. 58-61, 1991.

[23] G. M. Rayan, D. T. Stanfield, S. Cahill, S. D. Kosanke, and J. A. Kopta, "Effects of rapid pulsed $\mathrm{CO}_{2}$ laser beam on cortical bone in vivo," Lasers in Surgery and Medicine, vol. 12, no. 6, pp. 615-620, 1992.

[24] M. D. McKee, "Effects of $\mathrm{CO}_{2}$ laser irradiation in vivo on rat alveolar bone and incisor enamel, dentin, and pulp," Journal of Dental Research, vol. 72, no. 10, pp. 1406-1417, 1993.

[25] L. R. Friesen, C. M. Cobb, J. W. Rapley, L. Forgas-Brockman, and P. Spencer, "Laser irradiation of bone-II. Healing response following treatment by $\mathrm{CO}_{2}$ and Nd:YAG Lasers," Journal of Periodontology, vol. 70, no. 1, pp. 75-83, 1999.

[26] V. G. McDavid, C. M. Cobb, J. W. Rapley, A. G. Glaros, and P. Spencer, "Laser irradation of bone-III. Long-term healing following treatment by $\mathrm{CO}_{2}$ and Nd:YAG lasers," Journal of Periodontology, vol. 72, no. 2, pp. 174-182, 2001.

[27] M. Frentzen, W. Götz, M. Ivanenko, S. Afilal, M. Werner, and P. Hering, "Osteotomy with $80-\mu \mathrm{s} \mathrm{CO}_{2}$ laser pulseshistological results," Lasers in Medical Science, vol. 18, no. 2, pp. 119-124, 2003.

[28] Y. Nakamura, M. Hossain, H. Watanabe, H. Tokonabe, N. Matsumoto, and K. Matsumoto, "A study on the morphological changes of the rat mandibular bone with TEA $\mathrm{CO}_{2}$ laser," Journal of Clinical Laser Medicine and Surgery, vol. 17, no. 5, pp. 211-215, 1999.

[29] T. M. Williams, C. M. Cobb, J. W. Rapley, and W. J. Killoy, "Histologic evaluation of alveolar bone following $\mathrm{CO}_{2}$ laser removal of connective tissue from periodontal defects," The International Journal of Periodontics \& Restorative Dentistry, vol. 15, no. 5, pp. 497-506, 1995.

[30] O. Hamadah and P. J. Thomson, "Factors affecting carbon dioxide laser treatment for oral precancer: a patient cohort study," Lasers in Surgery and Medicine, vol. 41, no. 1, pp. 17-25, 2009.

[31] R. C. J. Verschueren, J. Koudstaal, and J. Oldhoff, “The carbon dioxide laser; some possibilities in surgery," Acta Chirurgica Belgica, vol. 74, no. 2, pp. 197-204, 1975.

[32] D. G. Nelson, M. Shariati, R. Glena, C. P. Shields, and J. D. Featherstone, "Effect of pulsed low energy infrared laser irradiation on artificial caries-like lesion formation," Caries Research, vol. 20, no. 4, pp. 289-299, 1986.

[33] A. L. McKenzie, "How far does thermal damage extend beneath the surface of $\mathrm{CO}_{2}$ laser incisions?" Physics in Medicine and Biology, vol. 28, no. 8, pp. 905-912, 1983.

[34] L. S. Krause, C. M. Cobb, J. W. Rapley, W. J. Killoy, and P. Spencer, "Laser irradiation of bone-I. An in vitro study concerning the effects of the $\mathrm{CO}_{2}$ laser on oral mucosa and subjacent bone," Journal of Periodontology, vol. 68, no. 9, pp. 872880, 1997. 
[35] S. Tatsumi, K. Ishii, N. Amizuka et al., "Targeted ablation of osteocytes induces osteoporosis with defective mechanotransduction," Cell Metabolism, vol. 5, no. 6, pp. 464-475, 2007.

[36] J. Berley, S. Yamano, and C. Sukotjo, "The effect of systemic nicotine on osseointegration of titanium implants in the rat femur," The Journal of Oral Implantology, vol. 36, no. 3, pp. 185-193, 2010.

[37] C. Johansson and T. Albrektsson, "Integration of screw implants in the rabbit: a 1-year follow-up of removal torque of titanium implants," The International Journal of oral \& Maxillofacial Implants, vol. 2, no. 2, pp. 69-75, 1987.

[38] P. R. Klokkevold, R. D. Nishimura, M. Adachi, and A. Caputo, "Osseointegration enhanced by chemical etching of the titanium surface: a torque removal study in the rabbit," Clinical Oral Implants Research, vol. 8, no. 6, pp. 442-447, 1997.

[39] A. Wennerberg, A. Ektessabi, T. Albrektsson, C. Johansson, and B. Andersson, "A 1-year follow-up of implants of differing surface roughness placed in rabbit bone," International Journal of Oral and Maxillofacial Implants, vol. 12, no. 4, pp. 486-494, 1997.

[40] D. Baker, R. M. London, and R. O’Neal, “Rate of pull-out strength gain of dual-etched titanium implants: a comparative study in rabbits," International Journal of Oral and Maxillofacial Implants, vol. 14, no. 5, pp. 722-728, 1999.

[41] P. R. Klokkevold, P. Johnson, S. Dadgostari, A. Caputo, J. E. Davies, and R. D. Nishimura, "Early endosseous integration enhanced by dual acid etching of titanium: a torque removal study in the rabbit," Clinical Oral Implants Research, vol. 12, no. 4, pp. 350-357, 2001.

[42] S. A. Cho and S. K. Jung, "A removal torque of the laser-treated titanium implants in rabbit tibia," Biomaterials, vol. 24, no. 26, pp. 4859-4863, 2003.

[43] J. Steigenga, K. Al-Shammari, C. Misch, F. H. Nociti, and H. L. Wang, "Effects of implant thread geometry on percentage of osseointegration and resistance to reverse torque in the tibia of rabbits," Journal of Periodontology, vol. 75, no. 9, pp. 12331241, 2004.

[44] G. Cordioli, Z. Majzoub, A. Piattelli, and A. Scarano, "Removal torque and histomorphometric investigation of 4 different titanium surfaces: an experimental study in the rabbit tibia," International Journal of Oral and Maxillofacial Implants, vol. 15, no. 5, pp. 668-674, 2000.

[45] N. Jakse, M. Payer, S. Tangl, A. Berghold, R. Kirmeier, and M. Lorenzoni, "Influence of low-level laser treatment on bone regeneration and osseointegration of dental implants following sinus augmentation: an experimental study on sheep," Clinical Oral Implants Research, vol. 18, no. 4, pp. 517-524, 2007.

[46] M. G. Correa, M. L. Gomes Campos, J. B. César-Neto, M. Z. Casati, F. H. Nociti, and E. A. Sallum, "Histometric evaluation of bone around titanium implants with different surface treatments in rats exposed to cigarette smoke inhalation," Clinical Oral Implants Research, vol. 20, no. 6, pp. 588-593, 2009.

[47] E. Slaets, I. Naert, G. Carmeliet, and J. Duyck, "Early cortical bone healing around loaded titanium implants: a histological study in the rabbit," Clinical Oral Implants Research, vol. 20, no. 2, pp. 126-134, 2009.

[48] S. Yokose and T. Naka, "Lymphocyte enhancer-binding factor 1: an essential factor in odontoblastic differentiation of dental pulp cells enzymatically isolated from rat incisors," Journal of Bone and Mineral Metabolism, vol. 28, no. 6, pp. 650-658, 2010.
[49] K. E. S. Poole, R. L. Van Bezooijen, N. Loveridge et al., "Sclerostin is a delayed secreted product of osteocytes that inhibits bone formation," FASEB Journal, vol. 19, no. 13, pp. 18421844, 2005.

[50] C. Colnot, D. M. Romero, S. Huang et al., "Molecular analysis of healing at a bone-implant interface," Journal of Dental Research, vol. 86, no. 9, pp. 862-867, 2007. 


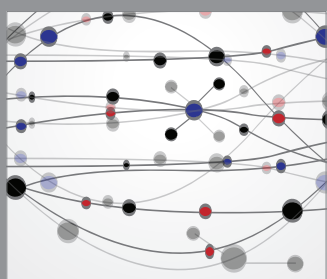

The Scientific World Journal

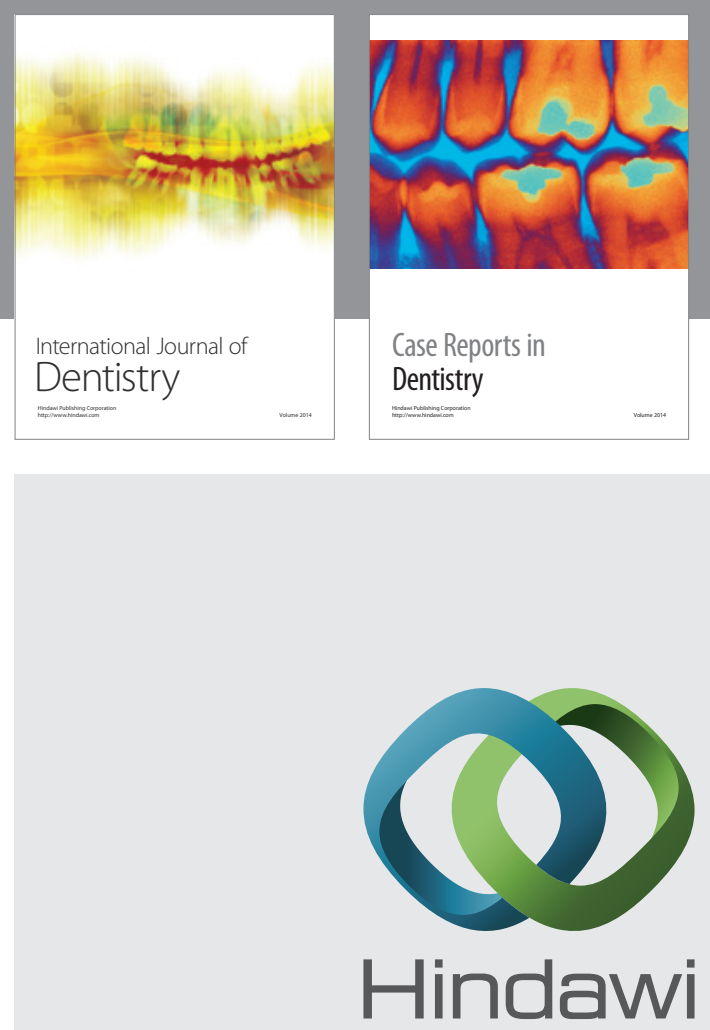

Submit your manuscripts at

http://www.hindawi.com
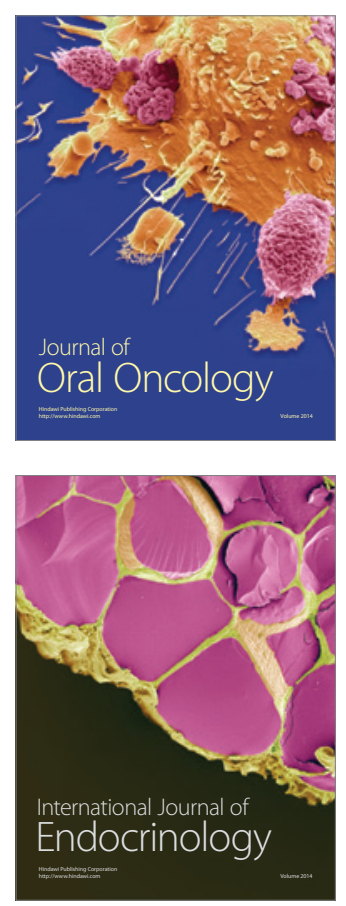
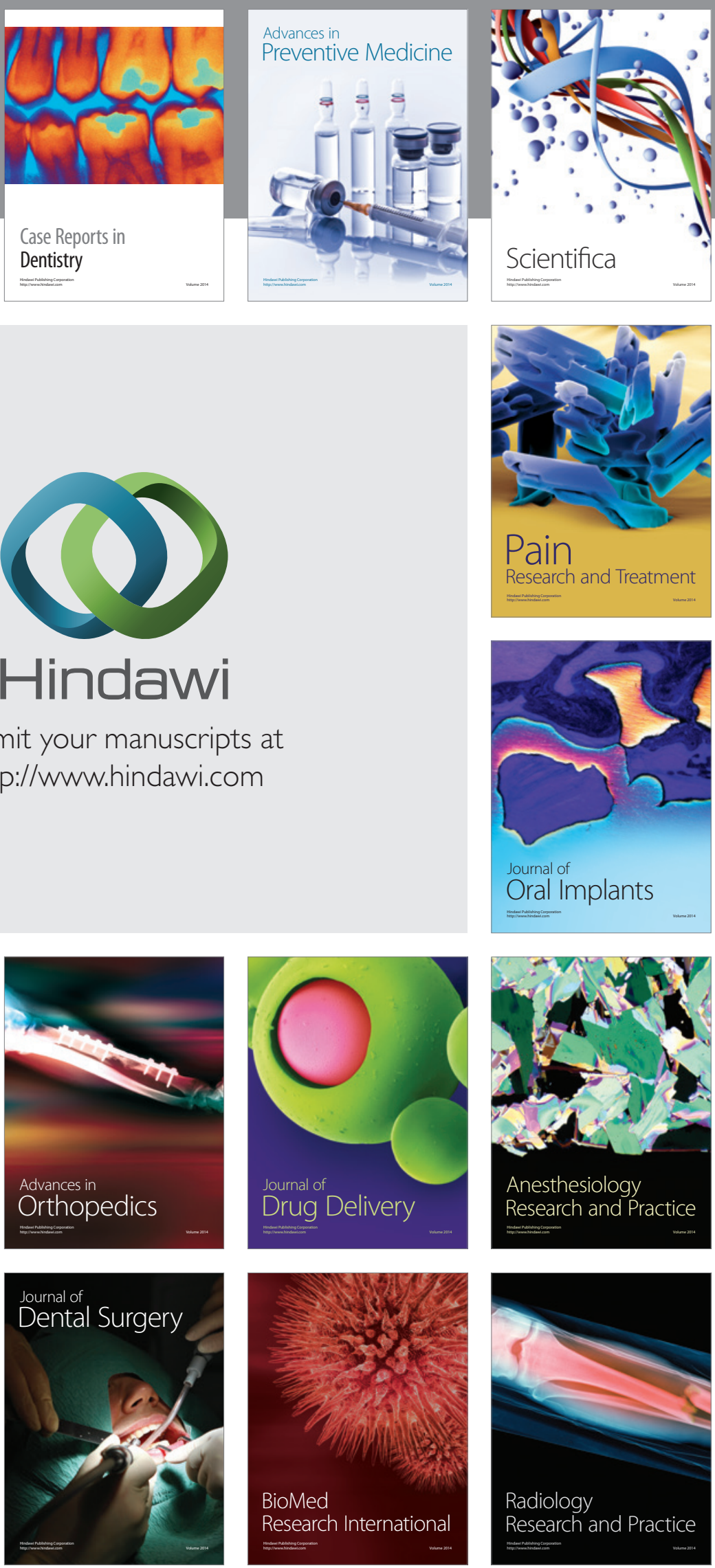